\title{
Research on the Disposal of Space Debris
}

\author{
Huaihui Liu, a , Zhijie Sun ${ }^{1}$, Tong Nie ${ }^{2}$, Furong Wang ${ }^{2}$ and Hongpeng Pan ${ }^{2}$ \\ ${ }^{1}$ Teaching and Research Department of Common Courses, Shandong Police College, Jinan, \\ 250101, China \\ 2 Department of Criminal Investigation, Shandong Police College, Jinan, 250101, China \\ IIhh_126126@126.com
}

\begin{abstract}
Keywords: Space debris distribution position model, Ophiuchus cost efficiency mode, Optimal profits model
\end{abstract}

\begin{abstract}
Since human launched the first man-made earth satellite, we have made more and more great achievements in this field. Accompanied with the rapid development, however, there are left multitudes of debris in the space. And the growth of space debris has a strong impact on the normal human space activities. We establish the Ophiuchus cost efficiency model to evaluate the cost of removing such space debris. From it, we can obtain the degenerate function of the spacecraft and establish the cost of the spacecraft based on the Bertrand model. We can get the regression equation of the laser instruments, space tongs and other cost respectively. And we predict the total cost which follows the linear relationship in next few years by the regression equation of the cost and set up the Ophiuchus cost efficiency model. Then, we establish the optimal profits model to choose the mixed use of exclusive use of the spacecraft with space tongs and the exclusive use of the spacecraft with laser. And, we can get the conclusion that every 5.6167 years the costs of sending spaceship will be lower half or the cost of sending spaceship towards space will lower $11.61 \%$ every year.
\end{abstract}

\section{Introduction}

Space debris is non-functional man-made objects located in earth orbit, including its pieces and parts. The U.S. space surveillance network monitors that the number of space debris in nearly a decade, especially in nearly five years, is increasing quickly, which means that the harm of the amount of space debris to space security has become very serious, especially in the low earth orbit. If their quantity reaches saturation, the probable collision of debris and satellite will increase, and it is more possible to produce a chain reaction due to collision, making orbital resources become ruins [1].

At present, there are lots of cleaning methods of space debris, which can be classified into three.

- Passive cleaning method.

- Active cleaning method.

- Hybrid cleaning method.

Amongst them, some research is still in design stage, a certain distance away from the actual application. With the development of technology, it will have great application value in the future.

We get a linear relationship between the total costs of the budget. We use the cost regression equation, carrying through budget for the coming years' costs, and build Ophiuchus cost efficiency model.

\section{The Cost of Spacecraft}

From 2011 to 2015, Russia is the only supplier of NASA, and NASA technical advantages make Russia a natural monopolist in the world market of spaceships. Similar to a monopoly, it is reasonable for us to assume that Russian contains the makers of the characteristic of the price. The most important is to achieve maximum profit. We assume that as long as the marginal cost (MC) is not more than marginal revenue (MR), the country will be willing to produce. Normally, the MC-curve is a u-shaped one which is relatively stable or slightly downward sloping at the beginning, and 
continues to increase after the growth in numbers [2]. This is mainly because resources will be used more effectively with the increase of the number.

Fig. 1 shows a typical demand-supply relationship of a monopoly market. In the figure, ATC is Average Total Cost. Due to its pricing power, the demand curve which is equal to price is higher than the cost curve. The model reaches its equilibrium when $\mathrm{MC}$ is equal to MR at point $\mathrm{H}$, with an ATC of $\mathrm{B}$, and a selling price of $\mathrm{A}$, which is $\$ 60$ million. According to this model, in the first five years, Russia through sending American astronauts can earn profit which is equivalent to the area of the rectangle ABFG [3]. But the benefits won't last forever. With the passage of time, more and more countries have the ability to provide foreign spacecraft for foreign countries, and all of them are willing to make such trading profits.

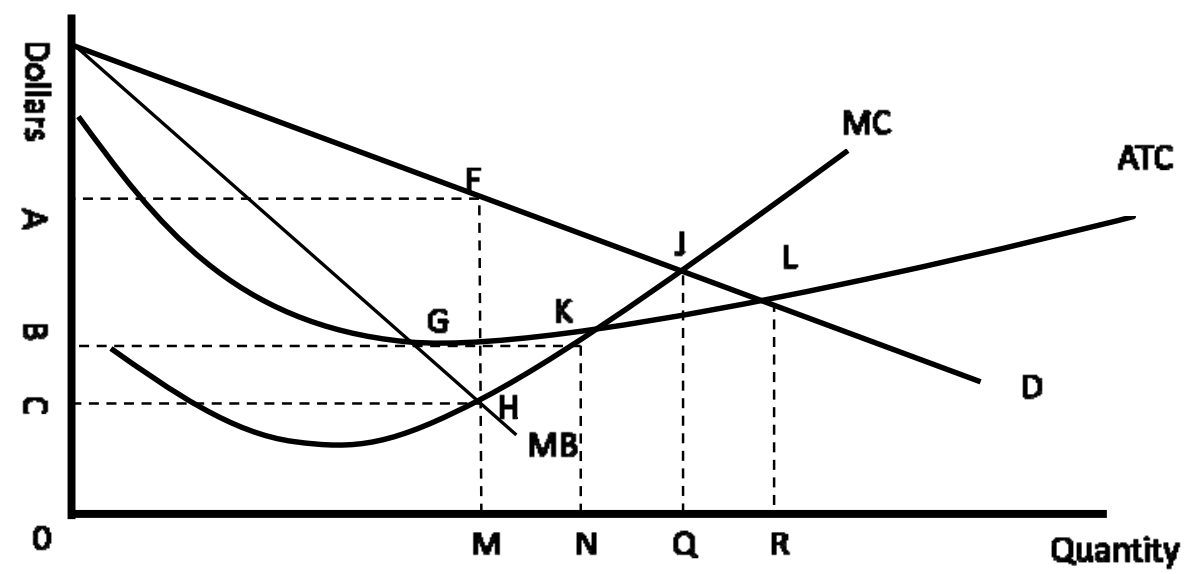

Fig. 1 Market with single seller

After 2015 the market can be called as oligopolistic competition, because more commercial companies and countries are able to provide shuttle for American astronauts. Traditionally, there are several theories which can describe such a market, including but not limited to Stackelberg theory, Cournot theory and Bertrand theory. We are now trying to find out the effect of competition on the price. Therefore, as to this problem, we select the Bertrand model [4].

In Bertrand model, the supplier offering lowest price wins the whole market, leading to fierce competition between oligopolists, driving prices down until to the marginal cost. Since the space shuttle is usually produced at a small number, we can roughly estimate the marginal cost, and then calculate the future cost of sending aircraft and laser.

The Moore's law for computer indicates that the computers' performance will double every 18 months. We find that it is possible to develop a similar law for space shuttles. We take launch data of three Chinese shuttles, Shenzhou 5, Shenzhou 6 and Shenzhou 7, as shown in Table 1 (in billion Yuan).

Table 1 Cost per Astronaut of Shenzhou Spaceships

\begin{tabular}{cccc}
\hline & Shenzhou 5 & Shenzhou 6 & Shenzhou 7 \\
Number of Astronauts & 1 & 2 & 3 \\
Year Launched & 2003 & 2005 & 2008 \\
Cost of Launching & 0.6 & 0.9 & 1 \\
Cost per Astronaut & 0.6 & 0.45 & 0.33 \\
\hline
\end{tabular}

By computing these data, we finally get the result of the space shuttle, namely, rising period $\mathrm{p}$ is equal to 5.6167 years. This means that every 5.6167 years, the cost of launching the space shuttle will be half of the price as it used to be five years earlier. In other words, the cost of launching the space shuttle will be cut by $11.61 \%$ a year.

We apply the data $11.61 \%$ to the price for the year 2015 , we can easily get the cost for the year 2016 to 2020, as shown in Table 2 (in million dollars). 
Table 2 Estimated Cost of Transportation from 2015 to 2020

\begin{tabular}{ccc}
\hline Year & Cost per Astronaut & Cost per Pound of Cargo \\
2015 & 60 & 0.0075 \\
2016 & 53.034 & 0.00662925 \\
2017 & 46.87675 & 0.005859594 \\
2018 & 41.43436 & 0.005179295 \\
2019 & 36.62383 & 0.004577979 \\
2020 & 32.37181 & 0.004046476 \\
\hline
\end{tabular}

We use the regression of sine function and polynomial function, getting the following two functions as Eq. 1 and Eq. 2.

$$
\begin{aligned}
& f(x)=4466.46172 \sin (0.15707963 x+0.93463288)-1244.625 \\
& f(x)=-41.135714 x^{2}+352.821428 x+2452.47714
\end{aligned}
$$

The MSE for the sinusoidal regression is 1466.63685 while the MSE for the polynomial one is only 169.770809 , which is far smaller than that of the sinusoidal one. Thus we choose the polynomial one as our regressed function.

In conclusion, the cost function for year 2016 to 2020 can be illustrated as followed Eq. 3 in which $\mathrm{n}$ represents the year.

$$
\mathrm{C}=0.8839^{\mathrm{n}-5}(60 x+0.0075(2000 x+y))-41.14 n^{2}+352.82 n+2452.48
$$

\section{Other Cost}

For small pieces, we take use of the laser carried on spacecraft to dispose small pieces directly. For larger pieces in high orbit, we make pieces fall to the earth's surface. For the larger pieces in low orbit, we choose to use mechanical tongs to grab, and then loose them in the earth's surface, making them hypergolic, in order to achieve the aim of disposing pieces. The specific distribution of pieces is shown in Table 3 . Therefore, the cost of spending on aircraft, in addition to the cost of the aircraft itself, also includes the cost of the laser, tongs, and space craft maintenance costs [5].

Table 3 the Specific Distribution of Pieces

\begin{tabular}{ccccccc}
\hline Height $(\mathrm{km})$ & $10 \mathrm{um}$ & $100 \mathrm{um}$ & $1 \mathrm{~mm}$ & $1 \mathrm{~cm}$ & $10 \mathrm{~m}$ & $1 \mathrm{~m}$ \\
\hline 300 & $3.736 \mathrm{E}+02$ & $1.217 \mathrm{E}+01$ & $1.891 \mathrm{E}-02$ & $6.070 \mathrm{E}-07$ & $6.230 \mathrm{E}-08$ & $3.620 \mathrm{E}-08$ \\
350 & $4.666 \mathrm{E}+02$ & $1.582 \mathrm{E}+01$ & $2.977 \mathrm{E}-02$ & $1.450 \mathrm{E}-06$ & $1.510 \mathrm{E}-07$ & $8.050 \mathrm{E}-08$ \\
400 & $5.466 \mathrm{E}+02$ & $1.899 \mathrm{E}+01$ & $3.966 \mathrm{E}-02$ & $2.580 \mathrm{E}-06$ & $2.510 \mathrm{E}-07$ & $1.200 \mathrm{E}-07$ \\
450 & $6.720 \mathrm{E}+02$ & $2.121 \mathrm{E}+01$ & $5.176 \mathrm{E}-02$ & $4.840 \mathrm{E}-06$ & $3.680 \mathrm{E}-07$ & $2.060 \mathrm{E}-07$ \\
500 & $7.521 \mathrm{E}+02$ & $2.443 \mathrm{E}+01$ & $6.437 \mathrm{E}-02$ & $6.870 \mathrm{E}-06$ & $6.930 \mathrm{E}-07$ & $4.280 \mathrm{E}-07$ \\
600 & $9.525 \mathrm{E}+02$ & $3.634 \mathrm{E}+01$ & $8.033 \mathrm{E}-02$ & $8.030 \mathrm{E}-06$ & $1.240 \mathrm{E}-06$ & $5.910 \mathrm{E}-07$ \\
700 & $1.228 \mathrm{E}+03$ & $5.394 \mathrm{E}+01$ & $1.033 \mathrm{E}-01$ & $1.410 \mathrm{E}-05$ & $1.620 \mathrm{E}-06$ & $5.290 \mathrm{E}-07$ \\
800 & $1.476 \mathrm{E}+03$ & $7.029 \mathrm{E}+01$ & $1.098 \mathrm{E}-01$ & $3.660 \mathrm{E}-05$ & $3.040 \mathrm{E}-06$ & $1.330 \mathrm{E}-06$ \\
900 & $1.720 \mathrm{E}+03$ & $1.006 \mathrm{E}+02$ & $6.390 \mathrm{E}-02$ & $9.500 \mathrm{E}-05$ & $2.810 \mathrm{E}-06$ & $7.580 \mathrm{E}-07$ \\
\hline 1000 & $2.046 \mathrm{E}+03$ & $1.094 \mathrm{E}+02$ & $1.712 \mathrm{E}-01$ & $3.600 \mathrm{E}-05$ & $3.280 \mathrm{E}-06$ & $1.270 \mathrm{E}-06$ \\
\hline
\end{tabular}

Variables in the model include the cost of the laser $C_{a}$, the cost of tongs $C_{c}$ and maintenance cost $\mathrm{C}_{\mathrm{m}}$, it can show as Eq. 4 . 


$$
\mathrm{C}^{\prime}=\mathrm{C}_{a}+C_{c}+C_{m}
$$

\section{The Cost of the Laser}

We assume that the cost of laser broken unit pieces is $X$, and remains the same, so $\mathrm{C}_{a}$ is a linear equation as Eq. 5.

$$
\mathrm{C}_{a}=K_{1} X
$$

\section{The Cost of Tongs}

We assume that the cost of each tong is $\mathrm{C}_{c}$, and remains the same, so $\mathrm{C}_{c}$ is a linear equation as Eq. 6 .

$$
\mathrm{C}_{c}=K_{2} Y
$$

\section{Maintenance Cost}

Maintenance cost associates with the service time of international spacecraft, and also relates to the frequency of flights. The longer the work time is, and the more frequent the flights are, the higher maintenance costs will be.

By examining the budget of the NASA spacecraft from 2011 to 2015 , we can easily get the maintenance cost of spacecraft as shown in Table 4 (the number beside the year represents its value in the functions later).

Table 4 the Budget of the NASA Spacecraft

\begin{tabular}{cc}
\hline Year & Budget $($ million dollars) \\
\hline $2011(1)$ & 2779.8 \\
\hline $2012(2)$ & 2983.6 \\
\hline $2013(3)$ & 3129.4 \\
\hline $2014(4)$ & 3221.9 \\
\hline $2015(5)$ & 3182.8 \\
\hline
\end{tabular}

Thus, the annual cost from 2011 to 2015 can be shown as the following Eq. 7.

$\mathrm{C}^{\prime}=K_{1} X+K_{2} Y+C_{m}$

\section{References}

[1] GUO Rong, Study on Space Debris Collision Early Warning and Maneuver Strategy to Low Earth Orbit Spacecraft. Paper for Master Degree[D], National University of Defense Technology (2005).

[2] PANG Bao-jun, HAN Zeng-yao, The Establish of Design of Space Debris Projection System. The third proceedings of the national space debris workshop, Beijing, 7(2002).

[3] LKatz, Mechanism for Spacecraft Charging Initiated Destruction of Solar Arrays in GEO, in Proc. AIAA 36 Aerosp. Sci,Meeting, Reno, NV, Vol. 98(1998).

[4] Chen Yi-jun, Discussion on Business Enterprise Operation Plan Optimization Model[J], Journal of WUT: Information \& Management Engineering, Vol.24,5(2002).

[5] LI Ling, CHEN Yun-xiang, LIU Yuan, Military Aircraft Safety Assessment Method Based on the ANP and GAHP[J], Systems Engineering, Vol.29,3(2011). 